\title{
EVOLUÇÃO DA POLÍTICA FLORESTAL PARANAENSE A PARTIR DA DÉCADA DE 90
}

\author{
Anadalvo Juazeiro dos Santos*, Alex Sandro Nogueira** \\ *Eng. Florestal, Dr., Depto. Economia Rural e Extensão, UFPR - ajsantos@ufpr.br \\ **Eng. Florestal, Mestrando em Eng. Florestal, UFPR - alexsandro@ufpr.br \\ Recebido para publicação: 24/03/2005 - Aceito para publicação: 28/05/2007
}

\begin{abstract}
Resumo
O setor florestal paranaense viveu na década de 90 uma fase de consolidação conquistada através do uso adequado da base florestal implantado durante a vigência dos incentivos fiscais nos anos 70 . O subsetor industrial manteve e ampliou os reflorestamentos verticalizados, e importantes iniciativas de políticas públicas buscaram atendê-lo. Mesmo assim, as principais ações desenvolvidas, pelo excessivo controle burocrático estatal, têm dificultado uma melhor distribuição da base florestal entre os diferentes segmentos rurais. $\mathrm{Na}$ área ambiental, foi registrada significativa recuperação da cobertura florestal, com o incremento das áreas em estágio inicial da sucessão florestal, bem como com a implementação de um programa de incentivos fiscais para a manutenção e criação de unidades de conservação. Apesar desse quadro, cabe ainda ao estado a importante missão de desonerar e desburocratizar o processo produtivo, buscando o ingresso de novos agentes no setor, como o são os pequenos e médios proprietários rurais.
\end{abstract}

Palavras-chave: Política florestal; Paraná; cadeia floresta-madeira.

\begin{abstract}
Evolution of the forest politics of the Parana state from the 90 's decade. The Parana's forestry sector lived in the 90's a stage of consolidation obtained through the appropriate use of the forestry base implanted mainly during the vigence of the fiscal incentives in the 70 's. The industrial sub-sector, maintained and enlarged the reforestation and for this segment, important initiatives from public politics intend to attend it. Even so, the mainly actions developed, by the excessive state's bureaucratic control, have difficult a better distribution of the forestry base among the several rural segments. In the environmental sector, significant recovery of the forestry covering was recorded with the increasing of the early stage of forestry succession, like wise with an implementation of a fiscal incentive program to the maintenance and creation of conservation unities. Despite of this situation, the state has an important mission to degenerate the productive process, seeking the ingression of news agents inside the sector, as the small an medium rural owners are.

Keywords: Forest politics; Paraná; Forest - wood - chain.
\end{abstract}

\section{INTRODUÇ̃̃̃O}

A exploração florestal no Brasil teve início em 1511, com a concessão de corte do pau-brasil (Caesalpinia echinata Lam) dada pela coroa portuguesa a Fernando de Noronha. A atividade extrativista da madeira constitui-se, até o século XVII, como principal fonte de divisas da Coroa portuguesa saída de terras brasileiras (ABIMCI, 2005).

No Paraná, estado com forte representatividade no negócio florestal brasileiro, a exploração de florestas iniciou oficialmente em 1765, com o advento de um decreto do Rei D. João V, de Portugal. O referido decreto autorizava o corte de pinheiros do planalto curitibano, para serem usados na construção da nau "São Sebastião". Porém, a falta de infra-estrutura, fato comum na colônia brasileira daquela época, fez com que a atividade exploratória madeireira se concentrasse na faixa litorânea do estado, mantendo-se assim até meados do século XVI, de forma incipiente (ABIMCI, 2005).

Somente em 1873, com a abertura da estrada da Graciosa, aliada à construção da estrada de ferro Curitiba-Paranaguá, em 1885, e do Ramal Morretes-Antonina, em 1891, a exploração florestal, 
notadamente da espécie Araucaria angustifolia, ganhou os planaltos paranaenses, dando início a uma das atividades econômicas mais importantes para o estado (ABIMCI, 2005).

Atualmente, o setor florestal destaca-se no cenário econômico do Paraná, sendo a madeira o segundo produto da pauta de exportações do agronegócio estadual, representando $8,6 \%$ do valor das exportações (EMATER, 2002).

Conforme dados publicados pela SEAB (2006), o Estado é responsável por 40\% das exportações brasileiras de madeira provinda de plantações e detém um dos maiores pólos moveleiros do país (Arapongas), que gera mais de 9.000 empregos diretos. O setor florestal é responsável por 8,3\% do Valor Bruto da Produção (VBP) do Paraná, gerando R\$ 80 milhões $(6,8 \%)$ para o Fundo de Participação dos Municípios (FPM), responsável pela geração de aproximadamente 55 mil empregos diretos, somente no segmento de serrados e processamento mecânico (17\% dos empregos do segmento no país) e no geral 76 mil empregos diretos e 158 mil indiretos.

Frente à importância socioeconômica e ambiental do setor florestal para o Paraná, o presente trabalho tem como objetivo compilar a evolução de medidas de políticas florestais adotadas pelo estado no decorrer da década de 90 até os dias atuais.

\section{A cobertura florestal paranaense}

As formações florestais naturais

Atualmente, as formações florestais naturais no Paraná totalizam 4,52 milhões de hectares, perfazendo um remanescente de $24,9 \%$ das áreas de florestas primitivas outrora existentes no estado. $\mathrm{Na}$ tabela 1 são apresentadas às áreas correspondentes aos remanescentes das formações florestais naturais por estágio sucessional e o respectivo percentual em relação à vegetação primitiva.

Tabela 1. Situação da vegetação arbórea no estado do Paraná.

Table 1. Situation of the arbores vegetation in the state of the Paraná.

\begin{tabular}{lccc}
\hline Vegetação arbórea & Situação atual (1000 ha) & $\mathbf{\%}$ & \% da vegetação primitiva \\
\hline Estágio inicial & $1.858,90$ & 41,1 & 10,23 \\
Estágio médio & $2.041,97$ & 45,2 & 11,24 \\
Estágio avançado & 617,02 & 13,7 & 3,40 \\
Total & $4.517,89$ & 100,0 & 24,87 \\
\hline
\end{tabular}

Fonte: SEMA, 2002.

Analisando os dados citados, é possível constatar que $41,1 \%$ do total remanescente das formações florestais no estado são representados por florestas em estágio inicial de sucessão.

As áreas de florestas em estágio médio e avançado de sucessão representam, respectivamente, $45,2 \%$ e $13,7 \%$ do total de florestas do estado.

É muito importante salientar que as formações florestais do estado do Paraná se distribuem em forma de mosaico, restando poucos locais, principalmente parques e unidades de conservação, onde ainda são encontradas áreas contínuas e extensas de florestas semelhantes às formações primitivas.

\section{Cultivos florestais}

Atualmente, o Paraná ocupa no ranking brasileiro a terceira posição em termos de área plantada com espécies florestais, destacando-se os gêneros Pinus e Eucalyptus (ABRAF, 2005).

Segundo o IAP (2002), em 2001 a área de florestas plantadas no estado do Paraná atingia o patamar de 688,4 mil hectares, ou seja, 3,4\% da área total do estado, sendo que, dessa área, aproximadamente 105,6 hectares eram compostos por espécies do gênero Eucalyptus e 532,4 mil hectares eram plantados com espécies do gênero Pinus. O restante da área, ou seja, 50,3 mil hectares, era composta por outras espécies arbóreas, principalmente araucária.

No que se refere à distribuição regional da área plantada com o gênero Pinus, existe uma concentração nas regiões de Telêmaco Borba, Jaguariaíva, Guarapuava e Vale do Ribeira, detentoras de $60 \%$ da área plantada no estado (IAP, 2002).

Os plantios com o gênero Eucalyptus estão concentrados nas regiões de Telêmaco Borba e Jaguariaíva, que, juntas, são detentoras de $80 \%$ da área plantada do estado (IAP, 2002). 


\section{Estoques de matéria-prima}

Com relação à oferta de madeira necessária ao atendimento da demanda dos diferentes segmentos industriais consumidores, diversas análises e estudos foram e ainda vêm sendo realizados no estado.

Mendes (2006) ressalta que, com o final dos incentivos fiscais, responsáveis por subsidiar grande parte da área plantada com florestas no estado do Paraná entre 1960 e 1980, o setor florestal paranaense passou por um período de estagnação até meados dos anos 90. Esse período caracterizou-se por baixos preços da madeira e pela redução de investimentos no setor.

A análise realizada por Freitas (2005) indicou que a partir de 2003/2004 existiria um déficit da oferta da madeira em relação à demanda no mercado paranaense, da ordem de 8,3 milhões de toneladas/ano, o que ocasionou uma demanda reprimida e a valoração da madeira do gênero Pinus.

É importante também ressaltar que, atualmente, no Paraná, a demanda por biomassa florestal para geração de energia é crescente. Mais recentemente, devido à valorização da madeira em toras, os resíduos florestais, que outrora atendiam parte dessa demanda, passaram a ser absorvidos pelas indústrias de painéis reconstituídos. A matéria-prima para energia tornou-se componente substituto da matériaprima à fabricação de chapas reconstituídas.

\section{Aspectos políticos e administrativos}

Com o advento da constituição de 1988, a competência para legislar sobre florestas, antes privativa somente da União, passou a ser também dos Estados membros da federação.

Durante os anos 80, a política paranaense de recursos naturais foi conduzida pelo Instituto de Terras, Cartografia e Florestas (ITCF), instituição vinculada à Secretaria da Agricultura do Paraná (SEAB)

No final dos anos 80, os principais programas editados pelo extinto ITCF (atual Instituto Ambiental do Paraná - IAP) foram o Programa de Desenvolvimento Florestal Integrado (PDFI) e o programa Paraná Rural, que impulsionaram a produção de mudas florestais pelo estado. A distribuição das mudas produzidas nesse período e a assistência técnica aos pequenos produtores rurais ficaram a cargo da Empresa Paranaense de Assistência Técnica e Extensão Rural (EMATER).

A promulgação da Lei $n^{0}$ 7.735, de 22 de fevereiro de 1989, responsável pela criação do Instituto Brasileiro do Meio Ambiente e dos Recursos Naturais Renováveis (IBAMA), na esfera federal, fez com que fossem desencadeadas pelo governo estadual reformas administrativas similares. A Lei Estadual $\mathrm{n}^{\circ}$ 10.066/92 extinguiu o ITCF e criou a Secretaria Estadual do Meio Ambiente (SEMA) e o Instituto Ambiental do Paraná (IAP).

À SEMA coube a missão de articular as políticas de meio ambiente, recursos hídricos, cartográficos e agrário-fundiários, enquanto ao IAP coube a missão de propor, coordenar e executar políticas de meio ambiente, conceder licenciamento ambiental e florestal, desenvolver programas de proteção ambiental, organizar e manter o Sistema Estadual de Unidade Conservação (SEUC) e administrar o Fundo Estadual do Meio Ambiente (FEMA), além de definir prioridades da política florestal estadual.

Outras instituições estaduais ficaram com o encargo de complementar as ações de estado em termos florestais, quais sejam:

a) Conselho Estadual de Meio Ambiente (CEMA): integrado à SEMA, é um órgão de caráter consultivo/deliberativo, de acordo com a legislação em vigor, representando o espaço de discussão da política ambiental para o estado, bem como o viés florestal dessa política.

b) Ministério Público Estadual (MP): instituição com função jurisdicional, incumbida da defesa da ordem jurídica, do regime democrático e dos interesses sociais e individuais indisponíveis.

Nos primeiros anos da década de 90, as pressões sociais decorrentes do movimento ambientalista fortaleceram as atividades de fiscalização do uso dos recursos florestais. Em janeiro de 1995, marcando uma nova fase da política florestal, foi promulgada a Lei Estadual $n^{\circ} 11.054$, que estabeleceu, entre outros instrumentos, a reestruturação administrativa do IAP, atividade esta que foi concluída pelo Decreto 884, de junho de 1995.

Sob a vigência da Lei 11.054 e do Decreto 884, foram criadas no IAP quatro diretorias: Diretoria Administrativa Financeira (DIAFI), Diretoria de Biodiversidade e Áreas Protegidas (DIBAP), Diretoria

FLORESTA, Curitiba, PR, v. 37, n. 3, set./dez. 2007. 
de Controle e Recursos Ambientais (DIRAM) e Diretoria de Desenvolvimento Florestal (DIDEF). Assim, ficaram bem definidas as atribuições administrativo-financeiras, de conservação ambiental, de licenciamento e fiscalização e de desenvolvimento florestal.

O ambiente institucional configurado a partir de 1995 possibilitou a criação e o desenvolvimento de diferentes programas, projetos e atividades que constituem a política estadual de desenvolvimento florestal, com o foco na recuperação e gestão estratégica dos recursos florestais.

\section{Principais programas, projetos e atividades}

\section{Reposição florestal obrigatória}

Em concordância com a Constituição federal, o Paraná insere em sua Constituição estadual atribuições legais acerca da reposição florestal obrigatória. Tais atribuições foram instituídas em 01 de dezembro de 1992, através da Lei 10.155.

O Sistema de Reposição Florestal Obrigatória (SERFLOR) atualmente vigente foi concebido com base no dispositivo constitucional estadual que determina a obrigatoriedade de todos os consumidores de matéria-prima de origem florestal efetuarem a reposição florestal em quantidade equivalente ao volume consumido. O SERFLOR está proposto em consonância com a Constituição estadual, Lei Estadual $\mathrm{n}^{\circ}$ 10.155, e com a Lei Florestal Estadual 11.054, de 1995. Recentemente, o Instituto Ambiental do Paraná (IAP) lançou a Coletânea SERFLOR, reunindo os fundamentos técnicos e os embasamentos legais, como o Decreto Estadual $\mathrm{n}^{\circ}$ 1.940/96, as Portarias Normativas, os formulários utilizados e instruções de procedimentos.

O SERFLOR tem como objetivo promover de forma auto-sustentada o consumo da matériaprima de origem florestal, tornando-se um instrumento de gestão destinado a implementar o reflorestamento junto aos consumidores de matéria-prima florestal, propiciando parcerias com os produtores rurais paranaenses.

A principal meta do SERFLOR é atingir a equivalência entre o volume de madeira explorado e o volume plantado em número de árvores no Estado do Paraná, garantindo a perpetuidade da base florestal e, em conseqüência, a manutenção e ampliação do nível de empregos do setor florestal.

\section{Atividades de fomento florestal}

As atividades de fomento florestal no estado do Paraná, desde o início dos trabalhos, eram baseadas na produção e distribuição de mudas, deixando a cargo dos produtores as demais atividades relacionadas à produção florestal, não havendo, assim, um enfoque sinérgico de acompanhamento técnico com a finalidade da efetividade do plantio, formação e condução de florestas nas pequenas e médias propriedades rurais.

No início da década de 90 , foram feitos os primeiros esforços para a produção de mudas de espécies nativas e exóticas nos viveiros estaduais. Nesse período, estima-se que eram produzidas anualmente 15 milhões de mudas.

A partir de 1997, com a criação do Programa Florestas Municipais, ocorreu uma mudança estratégica na política de fomento florestal anteriormente adotada, contando-se agora com a maior participação dos municípios. A partir da implantação desse programa, cada município passou a contar com secretarias de meio ambiente ou de outra secretaria vinculada à atividade florestal, como, por exemplo, secretarias de agricultura. Esse fato se configurou um marco no processo da descentralização da gestão florestal, uma meta do governo estadual da época.

A parceria entre estado e municípios elevou a produção anual de mudas para aproximadamente 30 milhões, atribuindo-se $70 \%$ dessa produção aos viveiros municipais.

A política estadual concebida no âmbito da Diretoria de Desenvolvimento Florestal (DIDEF) teve seu auge no final da década de 90, quando foi estimado um plantio de 70 milhões de árvores, com a participação significativa de pequenos e médios produtores rurais.

\section{A Reserva Florestal Legal e Áreas de Preservação Permanente}

O Sistema de Manutenção, Recuperação e Proteção da Reserva Legal e Áreas de Preservação Permanente (SISLEG) foi instituído pelo Decreto Estadual 387, de 3 de março de 1999, e regulamentado pela Portaria 100/99 do IAP/GP. Tem como objetivo principal regulamentar, através da averbação na matrícula do imóvel, as áreas de Reserva Legal, correspondentes a $20 \%$ da área do imóvel, conforme 
estabelece o Código Florestal de 1965, bem como garantir a existência das áreas destinadas à preservação permanente em todas as propriedades rurais do estado. Esse sistema complementar à postura federal tem provocado um ajustamento das condições documentais fundiárias no estado, pela necessidade do estabelecimento de demarcações e conferência entre o documento existente, seja posse ou domínio, e a realidade fática, ou área física do imóvel. Em outubro de 2001, a promulgação da Lei Federal 10.267 e dispositivos regulamentadores postulou a obrigatoriedade de recadastramento das propriedades rurais, considerando uma nova demarcação e medição de precisão com tecnologia específica do GPS (Global Positionning System).

\section{ICMS Ecológico}

O ICMS Ecológico tem com objetivo principal incentivar a criação e manutenção de áreas protegidas em âmbito municipal. Criado pioneiramente no Paraná, através da Lei Estadual de ${ }^{\circ}$ 59/91, contempla os municípios com Unidades de Conservação públicas ou particulares, Áreas Indígenas ou Faxinais, devidamente identificadas no Cadastro Estadual de Unidades de Conservação, assim como municípios onde existem mananciais de abastecimento de água.

Segundo Loureiro (2002), a partir de 1991 houve conversão de aproximadamente 215 mil hectares em Unidades de Conservação. No inicio da década de 90, a área destinada a Unidades de Conservação no estado era aproximadamente 11,3 mil hectares, passando para 226 mil hectares no ano de 2000. O aumento mais expressivo em relação à superfície bruta foi referente a Áreas de Proteção Ambiental (APA), enquanto o maior aumento da superfície líquida foi referente à criação de parques. Esses resultados são reflexos das orientações políticas efetuadas pelo órgão ambiental na época, consubstanciadas nas normas do próprio ICMS Ecológico, que prevêem o estímulo deliberado à criação e manutenção dos Parques, e não das Áreas de Proteção Ambiental, as quais, para tal, devem passar por um rigoroso processo até serem registradas no Cadastro Estadual de Unidades de Conservação, criando assim condições de crédito do ICMS Ecológico aos municípios.

Dos 399 municípios paranaenses, 228 são contemplados pelo ICMS ecológico, o que se refletiu, na década de 90 , num acréscimo de mais de $150 \%$ da área natural protegida no estado, bem como de mais de $100 \%$ na qualidade da proteção conferida a essas áreas.

\section{Fundo Estadual do Meio Ambiente}

O Fundo Estadual do Meio Ambiente (FEMA) foi instituído pela Lei Estadual 12.945, de 05 de setembro de 2000, e normatizado pelo Decreto 3.240, de 08 de dezembro de 2000. O FEMA tem como finalidade concentrar e destinar recursos arrecadados com multas ambientais, financiar planos, programas ou projetos que objetivem o controle, a preservação, a conservação e/ou a recuperação do meio ambiente, buscando descentralizar a execução dos projetos, com o intuito de tornar seus proponentes parceiros do governo estadual na solução das questões ambientais.

Segundo Loureiro (2002), o FEMA é administrado pelo Instituto Ambiental do Paraná, e os recursos financeiros são aprovados pelo Conselho Administrativo desse instituto, sendo aplicados em programas ou projetos relativos à educação ambiental, controle, monitoramento e recuperação ambiental, proteção dos recursos hídricos, conservação da biodiversidade, unidades de conservação, desenvolvimento florestal, pesquisa, desenvolvimento tecnológico, integração institucional, políticas públicas ambientais e a despesas correntes pertinentes à Secretaria de Estado do Meio Ambiente e Recursos Hídricos e do Instituto Ambiental do Paraná.

\section{Programa Rede da Biodiversidade - Paraná Biodiversidade}

Criado em 2002, o Programa Rede da Biodiversidade tem como objetivo principal a reorientação da política ambiental estadual, através do estabelecimento de diretrizes estaduais de planejamento, interligando esforços públicos e privados, compatibilizando os programas e projetos previstos e em andamento, tendo a formação de corredores ecológicos ao longo dos rios Tibagi, Ivaí, Piquiri e Iguaçu, garantindo assim um fluxo natural de diversidade biológica, além da preservação e melhoria da qualidade dos recursos hídricos.

O Paraná Biodiversidade é um programa do estado do Paraná, com o apoio financeiro do Fundo Mundial para o Meio Ambiente (GEF), através do Banco Mundial, cujo objetivo principal é recuperar a biodiversidade nos corredores Araucária, Iguaçu-Paraná e Caiuá-Ilha Grande, escolhidos pela 
importância estratégica de remanescentes de ecossistemas originais do Paraná, localizados principalmente em Unidades de Conservação.

A estratégia de tal programa, que previu a estruturação de um processo educativo da sociedade paranaense, de um sistema de fiscalização e controle mais eficiente, e de extensão rural, é voltada à recuperação da biodiversidade, ao desenvolvimento de uma agricultura de menor impacto sobre o ambiente e ao desenvolvimento de uma série de estudos visando a melhor gestão dos recursos naturais. Como resultante dessa estratégia, fragmentos de vegetação passarão a ser conectados por corredores.

As ações desse programa vêm sendo desenvolvidas em unidades operacionais denominadas corredores de biodiversidade, tendo as microbacias hidrográficas e as propriedades nelas inseridas como unidades de trabalho.

Efetivamente, o Programa Paraná Biodiversidade foca sua atuação nas seguintes áreas:

- Corredor Araucária: situado na região centro-sul paranaense, onde estão os principais remanescentes da Floresta Ombrófila Mista ou Floresta com Araucária, esse corredor abrange 11 municípios, 90 microbacias e 3 unidades de conservação, especificamente, o Parque Estadual das Araucárias, a Reserva Florestal do Pinhão e a Estação Ecológica do Rio dos Touros.

- Corredor Iguaçu-Paraná: situado no oeste e sudoeste paranaense, componente da Floresta Estacional Semidecidual, esse corredor abrange 26 municípios, 70 microbacias e 3 unidades de conservação, como o Parque Nacional do Iguaçu, o Parque Estadual do Rio Guarani e uma área de importante interesse ecológico, conhecida como Cabeça do Cachorro.

- Corredor Caiuá-Ilha Grande: componente da região noroeste do Paraná, é composta pela Floresta Estacional Semidecidual, além de áreas de várzeas e ilhas do rio Paraná. Alcança 26 municípios, 120 microbacias e 3 unidades de conservação, como a Reserva Biológica de São Camilo, a Estação Ecológica do Caiuá e a Área de Proteção Ambiental (APA) das ilhas e várzeas do Rio Paraná.

\section{Programa de Cultivos Florestais}

O mais recente esforço governamental voltado ao setor florestal foi a criação do Programa de Cultivos Florestais, lançado em 22 de maio de 2006. Esse programa tem como principal objetivo ampliar a base florestal produtiva do estado do Paraná sob a égide da sustentabilidade, incorporando pequenos e médios produtores rurais na cadeia produtiva da madeira, com a finalidade da geração de trabalho e renda. Para tanto, estão sendo transferidas as atribuições sobre florestas produtivas da Secretaria de Estado do Meio Ambiente para a Secretaria de Estado da Agricultura e do Abastecimento.

\section{Atividades de extensão florestal}

Atualmente, as ações de extensão rural do estado do Paraná são desenvolvidas por diversos órgãos de apoio, notadamente pelo Instituto Paranaense de Assistência Técnica e Extensão Rural (EMATER). Essa empresa, desde o final da década de 90, vem desenvolvendo programas florestais de fomento em parceria com a iniciativa privada, como o Projeto Madeira. Esse projeto objetiva inserir os pequenos e médios agricultores na atividade florestal. Apesar de uma abrangência ainda restrita, a proposta tem permitido um maior envolvimento dos agricultores na atividade florestal e, dessa forma, contribui para uma discussão mais abrangente da problemática ambiental relacionada à ampliação dos reflorestamentos e à consolidação da base florestal paranaense. Assim como o Projeto Madeira, o cultivo de palmeiras para produção de palmito e a heveicultura também têm demandado ações de assistência técnica e de extensão na área florestal.

\section{A atividade de pesquisa florestal}

No período de análise do presente trabalho, em âmbito nacional, a pesquisa florestal obteve avanços significativos em todas as áreas de conhecimento da atividade florestal. No que se refere somente a esforços do governo estadual, destacam-se os programas e projetos desenvolvidos pelo Instituto Agronômico do Paraná (IAPAR).

Vinculado à Secretaria de Estado da Agricultura e do Abastecimento (SEAB), o IAPAR tem atuado na área florestal mais notadamente nas seguintes linhas de pesquisa: 
- Introdução, coleta, avaliação e conservação de germoplasma de espécies florestais, para uso em sistemas agroflorestais ou talhões puros, e em recuperação e proteção de áreas degradadas;

- Estudo e desenvolvimento de sistemas agroflorestais;

- Estudos em tecnologias de propagação e manejo de recursos florestais para produção de energia, madeira e produtos florestais não-madeireiros;

- Utilização de espécies florestais em proteção e recuperação ambiental.

Atualmente, no IAPAR, estão em andamento nove programas relacionados à pesquisa florestal, quais sejam:

- Avaliação de clones de seringueira nas condições edafoclimáticas das regiões norte, noroeste e litorânea do estado do Paraná.

- Produção de mudas de seringueira e influência de parasitas do solo na seleção de portaenxertos;

- Adubação da seringueira nas condições de viveiro, seringal em formação e seringal em produção na região noroeste do estado do Paraná.

- Desenvolvimento de sistemas agrossilviculturais adaptados ao Paraná.

- Manejo florestal, reflorestamento e recuperação de áreas degradadas.

- Desenvolvimento e adaptação de tecnologia para utilização da Casuarina equisetifolia como espécie florestal de uso múltiplo.

- Manutenção de germoplasma de espécies florestais potenciais.

- Monitoramento de seqüestro de carbono em plantações de seringueira.

- Produção e fornecimento de mudas de seringueira para propriedades de agricultura familiar no Vale do Ribeira e Litoral do Paraná.

\section{CONSIDERAÇÕES FINAIS}

A importância da atividade florestal paranaense tanto em termos econômicos como ambientais e sociais, aliada ao aumento das pressões sobre o conjunto dos recursos ambientais, vem impulsionando as ações do estado através da sistematização e criação de programas e dispositivos legais.

Entretanto, a formulação de uma política específica para os recursos florestais, tanto no que se refere aos aspectos conservacionistas quanto aos aspectos produtivistas, é um desafio a ser atingido.

Analisando-se a política florestal paranaense sob uma perspectiva histórica, é possível compreender os motivos que desencadearam os problemas florestais atuais. Do ponto de vista da exploração dos recursos, até pouco mais da metade do século passado, a atividade florestal no estado teve um caráter meramente extrativista. Essa característica foi paulatinamente substituída com a implantação de maciços florestais homogêneos.

Sob o ponto de vista da administração pública voltada às florestas, o período analisado foi marcado por sucessivas mudanças institucionais. As diferentes instituições encarregadas da questão tiveram também enfoques diversos em relação aos recursos florestais. Dessa forma, a descontinuidade das ações e a ausência de uma visão abrangente que abordasse de maneira equilibrada todas as funções florestais foram a tônica do período.

A partir da década de 90 , a normatização sobre a atividade florestal paranaense, bem como sua aplicação, ficou sob a responsabilidade de órgãos ambientais, e esse foi o tom dado à política florestal do estado. Esse fato ficou evidenciado pela predominância de programas voltados para a preservação e/ou recuperação das áreas florestais naturais.

Uma das principais constatações sobre a evolução da política florestal paranaense, nesse período, foi o crescente esforço para a recuperação da cobertura florestal natural, através de diversos programas implementados pelo governo estadual.

Os pontos negativos da política florestal estão fortemente ligados à ausência de uma política de incentivos econômicos por parte do governo estadual apesar do apoio federal nessa área. Esse fato tem exigido a criatividade, em especial, de pequenos empreendedores, frente à escassez de recursos. 
Os principais desafios da política florestal no Paraná são promover o negócio florestal, buscar maior competitividade no mercado internacional como forma de superar os fortes aumentos dos custos das matérias-primas e insumos e absorver a forte valorização cambial que recentemente vem freando as exportações desse que é um tradicional setor exportador.

Além disso, será importante uma postura firme por parte das autoridades estaduais ligadas à questão, no sentido de formular políticas de incentivo ao plantio de florestas, como forma de ampliar a oferta de madeira para o mercado interno e externo.

\section{REFERÊNCIAS}

ASSOCIAÇÃO BRASILEIRA DOS PRODUTORES DE FLORESTAS PLANTADAS. Anuário Estatístico ABRAF 2006 (Ano base 2005). Disponível em: <http://www.abraf.com.br>. Acesso em: 30 mar. 2006.

ASSOCIAÇÃO BRASILEIRA DA INDÚSTRIA DE MADEIRA PROCESSADA MECANICAMENTE. Setor de processamento mecânico da madeira no estado do Paraná. Disponível em: $<$ http://www.abimci.com.br>. Acesso em: 11 maio 2004.

FREITAS, A. R. Reflorestamento e desenvolvimento sustentável: as perspectivas da cadeia dos negócios com madeira no Sul do Brasil. Disponível em: <http://www.sbs.org.br>. Acesso em: 15 de maio de 2005 .

INSTITUTO PARANAENSE DE ASSISTÊNCIA TÉCNICA E EXTENSÃO RURAL. Relatório de gestão 1999 - 2002. Disponível em: <http:// www.emater.pr.gov.br/>. Acesso em: 10 mar. 2006.

INSTITUTO AMBIENTAL DO PARANÁ. Plano Estadual de conservação e uso do solo - 2003. Disponível em: <http:// www.pr.gov.br/iap/>. Acesso em: 11 maio 2004.

INSTITUTO AMBIENTAL DO PARANÁ. Desenvolvimento florestal (1995 - 2002). Disponível em: $<$ http:// www.pr.gov.br/iap/>. Acesso em: 11 maio 2004.

INSTITUTO AMBIENTAL DO PARANÁ - Coletânea - SERFLOR, 2000.

LOUREIRO, W. Contribuição do ICMS ecológico à conservação da biodiversidade no Estado do Paraná. 189 f. Tese (Doutorado em Engenharia Florestal) - Setor de Ciências Agrárias, Universidade Federal do Paraná, Curitiba, 2002.

MENDES, J. Mercado brasileiro de madeira de Pinus, 2006. Disponível em: <http:// www.remade.com.br/>. Acesso em: 30 de julho de 2006.

PARANÁ. SECRETARIA DA AGRICULTURA E DO ABASTECIMENTO. Programa de Cultivos Florestais do Paraná. Curitiba, 2006.

PARANÁ. SECRETARIA ESTADUAL DO MEIO AMBIENTE. O estado atual da cobertura florestal no Paraná - 2002. Disponível em: <http:// www.pr.gov.br/sema/>. Acesso em: 06 julho 2005. 